\title{
Influence of Seismic Behavior Factor on the Design of Building Structures for Low Seismic Demands Regions
}

\author{
Alejandro Hernández-Martínez ${ }^{1, *}$, Andrés E. Ortíz-Vargas ${ }^{2}$, Adrián D. García-Soto ${ }^{1}$, \\ Jesús G. Valdés-Vázquez ${ }^{1}$ and Mabel Mendoza-Pérez ${ }^{1}$
}

${ }^{1}$ Civil Engineering Department, Engineering Division, Guanajuato Campus, Universidad de Guanajuato. Av. Juárez 77,
Zona Centro, Guanajuato, Gto., México. CP 36000
${ }^{2}$ Civil Engineering Faculty, Universidad Michoacana de San Nicolás de Hidalgo. Morelia, Mich., Mexico. CP 58030.

\begin{abstract}
The use of reduced seismic forces obtained from elastic response spectra analysis is a common practice for structural design purposes. This procedure is used: (a) To take advantage of the nonlinear behavior of the structural elements that conform the entire structure, and (b) To reduce the initial cost of the construction, allowing certain degree of damage if a severe earthquake occurs, but trying to avoid collapse with good structural design and construction detailing. In this paper, structural analyses were performed using several seismic reduction coefficients and the considered structures were designed for low seismic design regions according to the Mexico construction codes for both, serviceability limit states and ultimate limit states. Results show that the final design is strongly dependent on allowed interstory drift, associated to lateral displacements. Results also showed that, reducing significantly the seismic forces is not directly associated with a reduction in the initial cost of the structure, i.e., the final design for different seismic behavior factor may have similar seismic vulnerability.
\end{abstract}

Keywords: Building design, initial cost, seismic force reduction, seismic reduction factor.

\section{INTRODUCTION}

Designing a structure to avoid damage during its lifetime could be a very difficult (or/and costly) goal. If the structure is built on a region with considerable degree of seismic hazard, this goal can be almost impossible to achieve due to the associated high construction cost. On the other hand, if structural elements for such structure are designed to elastically withstand lower seismic demands, the initial construction cost may be lower as well. However, since the lateral resistance is reduced, some structural elements may have nonlinear behavior during an earthquake, and this nonlinear behavior is usually associated with certain degree of damage.

In the current seismic design practice, nonlinear behavior is not necessarily associated with the collapse of the structure. The nonlinear behavior can be used to improve the structural response by (a) concentrating the damage in a few locations (b) dissipating the seismic energy, (c) reducing the initial cost of the structure, (d) avoiding partial or total collapse, and (e) taking advantage of the overstrength of materials among other features [1-4]. To have a good structural behavior several issues need to be considered, like an adequate structural concept, an appropriate detailing of the elements to allow nonlinear behavior and sufficient knowledge of materials among other issues related to the design and construction process $[3,4]$.

*Address correspondence to this author at the Civil Engineering Department, Engineering Division, University of Guanajuato. Av. Juárez 77, Zona Centro, Guanajuato, Gto., México. CP 36000; Tel: +52 (473) 1020100 ext. 2235; E-mail: alejandro.hernandez@ugto.mx

1874-1495/15
If a severe earthquake occurs, the materials used to build structural elements may exhibit linear force-displacement relationships at the initial stages of the event. However, at the intense phase of the seismic event the materials may show nonlinear behavior, undergoing lateral displacements and interstory drifts several times beyond the yield point or the linear strength. Under the hypothesis that a structure is able to dissipate the energy associated to an equivalent elasto-plastic system with a ductility $\mu$ (see Fig. (1) and eq. 1 ), the structure can be designed with a reduced capacity $\mu$ times less than the corresponding structure with elastic behavior $[1,3]$.

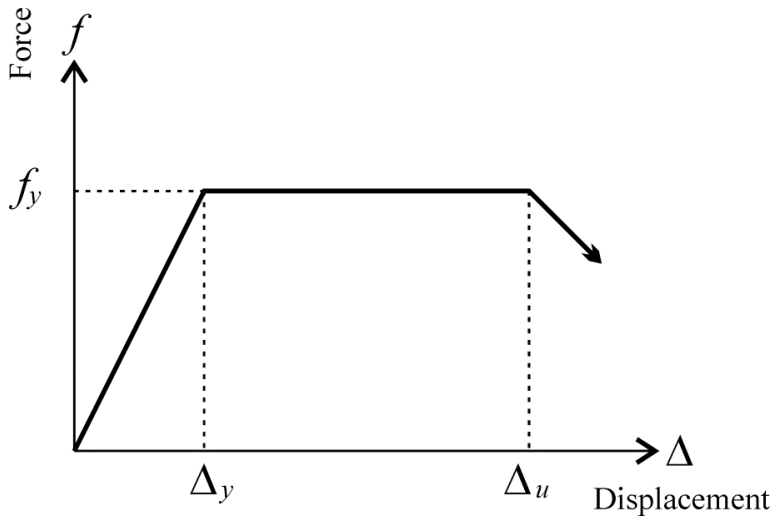

Fig. (1). SDOF system with elasto-plastic relationship.

Therefore, the required capacity (or strength $f_{y}$ ) for a single degree of freedom (SDOF) system with elasto-plastic 
relationship, is $\mu$ times less than the corresponding elastic SDOF system. This assumption enables an inelastic system with lower capacity to withstand an earthquake, since the additional energy that is introduced to the system is dissipated by hysteresis loops.

If an elasto-plastic SDOF system is able to develop a ductility $\mu$ defined by eq. (1) when an earthquake occurs, the system can be designed to have a lateral load strength obtained from the reduction of spectral acceleration computed for a linear SDOF system with the same natural frequency and damping, but divided by $\mu$. This assumption is reasonably valid for systems with natural period significantly greater than the natural period of the soil, while the assumption is not so adequate for SDOF systems with natural period similar to the soil, where the reduction decreases significantly.

$\mu=\frac{\Delta_{u}}{\Delta_{y}}$

where:

$\Delta_{u}=$ Ultimate displacement

$\Delta_{y}=$ Yield or strength displacement

$\mu=$ Ductility relationship

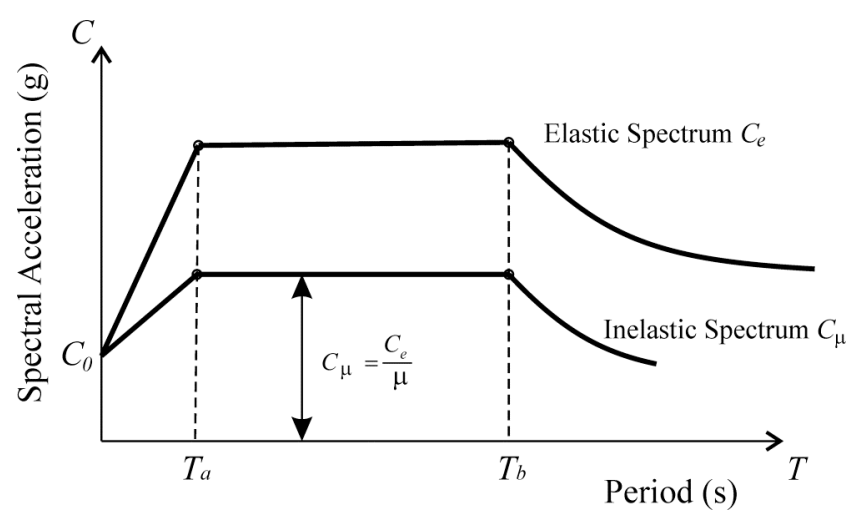

Fig. (2). Elastic spectrum and inelastic design spectrum.

For multi-degree of freedom (MDOF) systems the ductility is not exactly the same expressed in eq. (1), but it represents the capacity of the structure to dissipate seismic energy, the overstrength of structural elements and the redundancy of the MDOF system, and all this is included in the so-called seismic behavior factor (or reduction factor). According to Mexico construction requirements [5-7] a linear variation from 1 to $\mu$ of the reduction factor must be adopted. Thus, several inelastic design spectra can be obtained considering the expected ductility of the structure to be designed. The above mentioned procedure is depicted in Fig. (2), (modified from [7]).

Reducing seismic forces to allow nonlinear behavior in the designed structural elements is inherently related to an acceptable damage level, because seismic energy dissipation is necessary, so that the structural elements are able to develop hysteresis loops, and this is only possible if certain level of damage and degradation of the elements occur. Reducing the seismic forces using certain seismic behavior factor $\mu$ (defined like $Q$ or $R$ in several design codes [6-10]) implies a reduction in the expected strength of the element, and therefore less material must be needed, reducing the initial cost of the structure. However, in addition to check the strength, insterstory drifts and lateral displacements must be checked to ensure that the structure does not exhibit excessive damage, and that the contents and nonstructural elements are not affected significantly. The designer should be aware that a nonlinear elasto-plastic behavior is assumed, therefore if the displacements are obtained from a linear procedure, they should be amplified accordingly by the expected seismic behavior factor $\mu$.

The use of the seismic behavior factor to reduce the seismic forces for design is a common worldwide practice. This reduction affects the final design and, therefore it is expected that the initial cost of the structure is reduced respect to a linear elastic behavior. For regions associated to high spectral ordinates, a significant reduction of the initial cost is expected; in contrast, in regions where seismic demands are not so high, the reduction in the seismic forces may not have a significant impact on the initial cost of the structure.

\section{OBJETIVE}

The main objective of this study is to assess the impact of the use of several values of the seismic behavior factor $\mu$ on the design of typical structures located on a low seismic activity region in central Mexico (Guanajuato State). To achieve this, the structures are analyzed and designed with no force reduction (i.e. $\mu=1$ ), and also using other values of $\mu$ according to local construction code requirements. The design spectra are defined according the Manual de Diseño de Obras Civiles - Diseño por Sismo [7] since this handbook has the most complete estimation of the seismic demands in Mexico, and is widely used to estimate the seismic forces for almost any kind of structure. Additionally, seismic vulnerability of these kind of structures respect to code requirements can be evaluated depending on the final designs.

\section{METHODOLOGY}

\subsection{Analysis Model}

The basic structure model is showed in Fig. (3). The model corresponds to a $33.5 \mathrm{~m}$ high building (11 levels), 24 $\mathrm{m}$ long and $18 \mathrm{~m}$ wide for residential use. The structure consists of perpendicular frames of $6 \mathrm{~m}$ spans $3.5 \mathrm{~m}$ high in the first level and $3.0 \mathrm{~m}$ at higher levels. The floor systems are considered composite sections of steel sheets at the bottom and reinforced concrete on the top. Diaphragms are considered rigid for the analysis.

\subsection{Analysis and Design Considerations}

The structural elements are W-shape steel ASTM-A992 for beams and columns designed according to [11]. Live loads are defined according to [12] for residential use, and dead loads are estimated in $5.106 \mathrm{kPa}$ for intermediate levels and $5.743 \mathrm{kPa}$ for roof level. The seismic loads are estimated according to [7], considering the structures as located on seismic zone B and a soil type I, i.e., a stiff soil is considered. Seismic behavior factors of 1,2 and 3 are used for design purposes obtaining the design spectra showed in Fig. (4). 


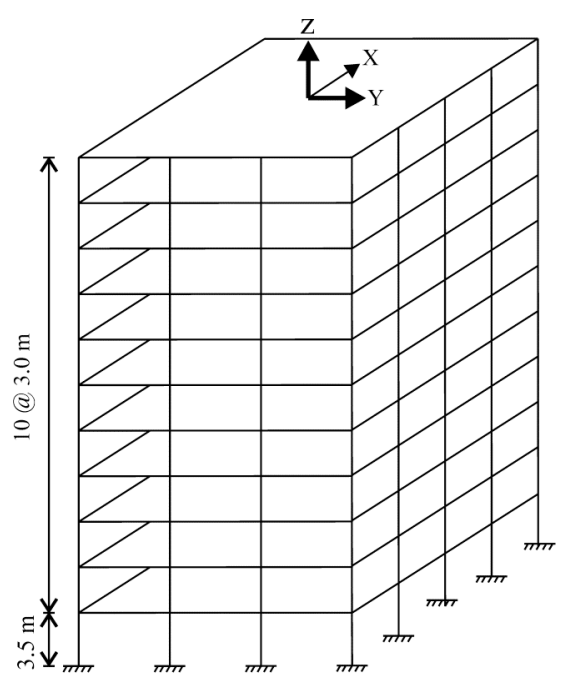

a) 3D Structural Model

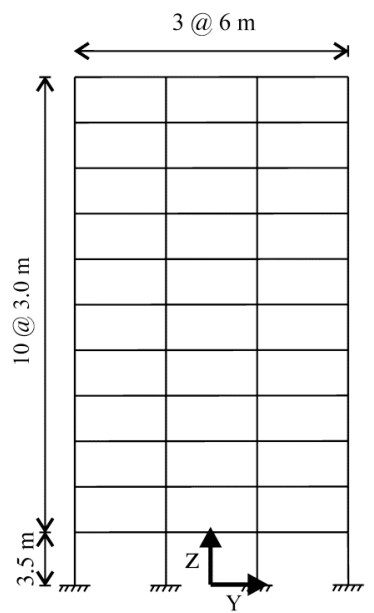

b) YZ plane view

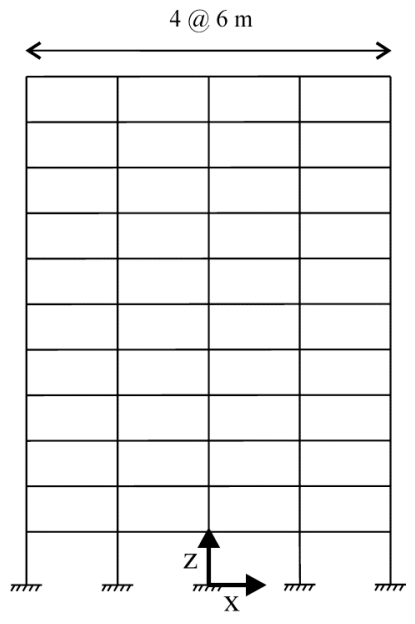

c) XZ plane view

Fig. (3). Basic model for analysis and design.

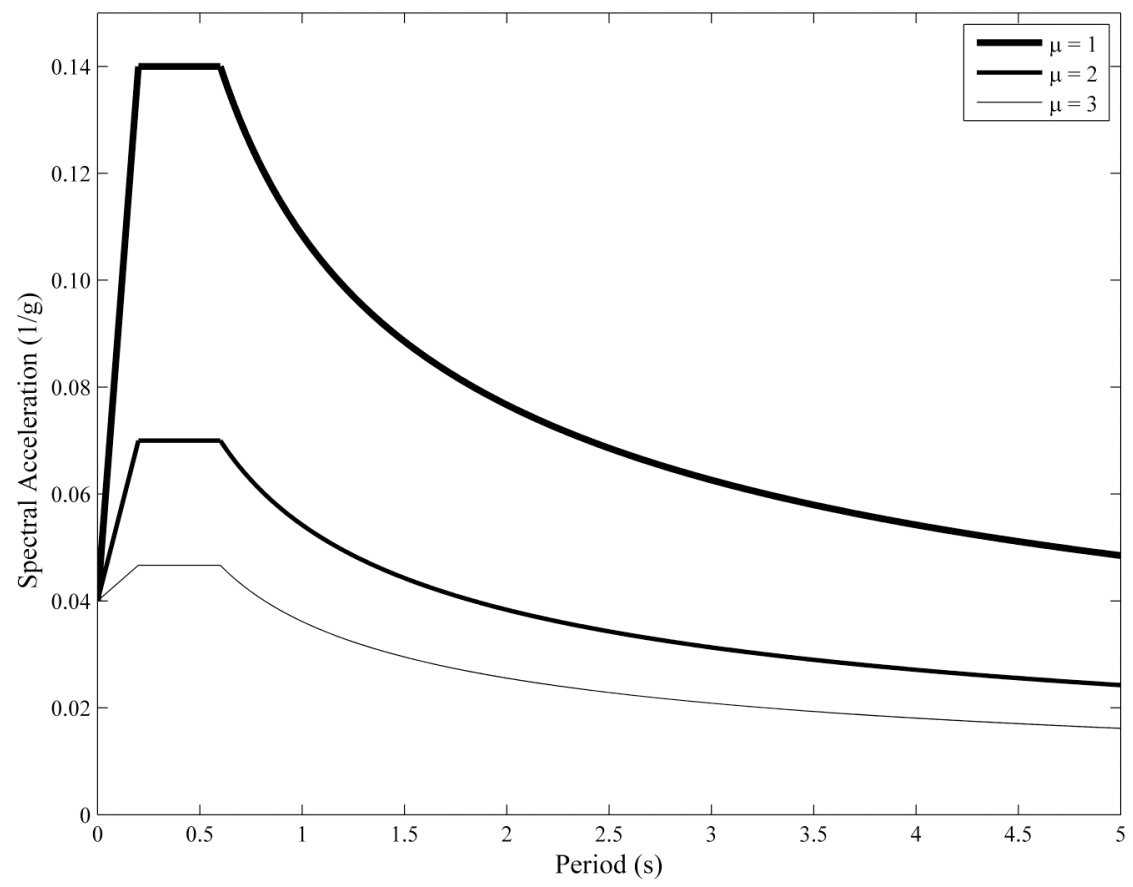

Fig. (4). Design spectra used for design.

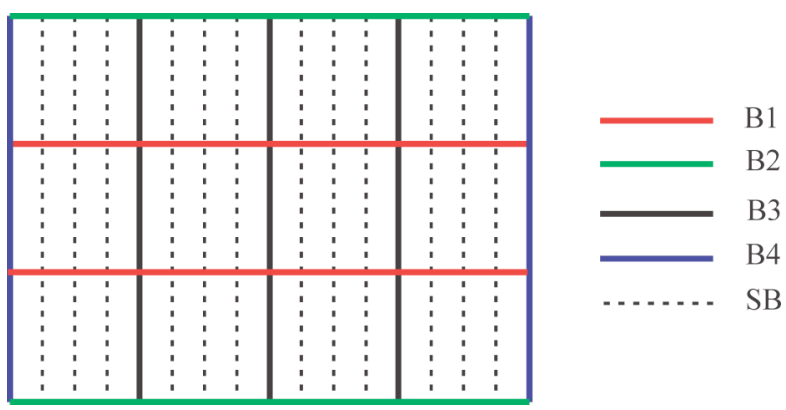

Fig. (5). Beam distribution.

Figs. (5-7) show the arrangement of the structural elements and its orientation. For Figs. (5 and 6) the equal line type and color means that the structural element has the same shape. An elevation view of the columns is showed in Fig. (7).

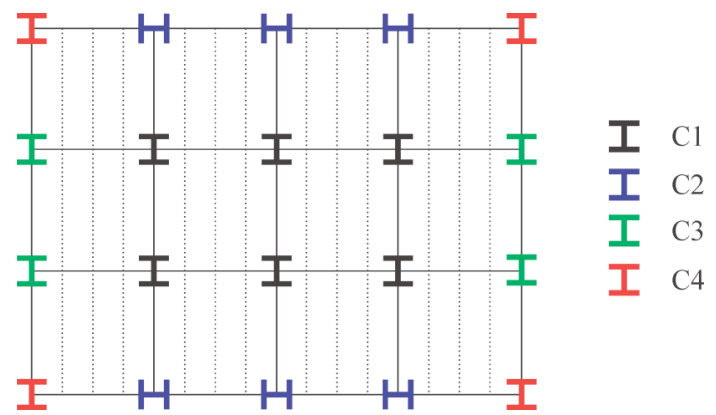

Fig. (6). Plan view of column distribution.

Load combinations used for design are those defined according to [12]. Load combinations used to review strength requirements of the structural elements correspond to eqs. (2) to (4). 


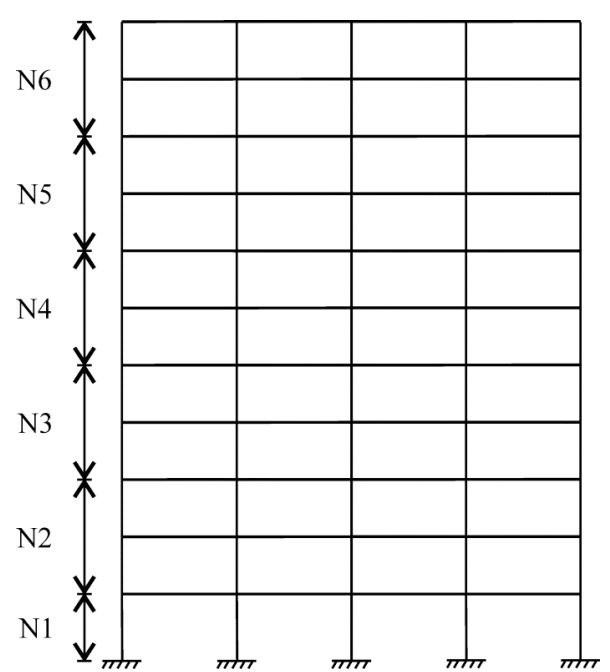

Fig. (7). Elevation view of column distribution.

$1.4 D L+1.4 L L_{\max }$

$1.1 D L+1.1 L L_{i} \pm 1.1 S_{x}$

$1.1 D L+1.1 L L_{i} \pm 1.1 S_{y}$

Load combinations used to review serviceability limit states, related to interstory drift and lateral displacement are defined by eqs. (5) to (7).

$D L+L L_{\max }$

$D L+L L_{i} \pm S_{x}$

$D L+L L_{i} \pm S_{y}$

where:

$D L=$ Dead load

$L L_{i}=$ Instant live load

$L L_{\text {max }}=$ Maximum live load

$S_{x}=$ Seismic loads in $X$ axis direction

$S_{y}=$ Seismic loads in $Y$ axis direction

According to [12], live loads are defined for three cases. The maximum live load $L L_{\max }$ must be used to check gravitational conditions. The instantaneous live load $L L_{i}$ must be used when an intense but short time load is acting in the structure, like seismic or wind load. $L L_{i}$ is expected to be less than $L L_{\max }$ because the probability that an intense earthquake (or wind) occurs when the maximum live load is presented is very low. Finally an average live load $L L_{\text {med }}$ must be used when a long term condition is checked; this kind of live load is not used in the presented study.

For combinations that include earthquake forces it is important to note that $100 \%$ of the demand associated to Fig. (4) in the direction of analysis, and $30 \%$ of the same demand

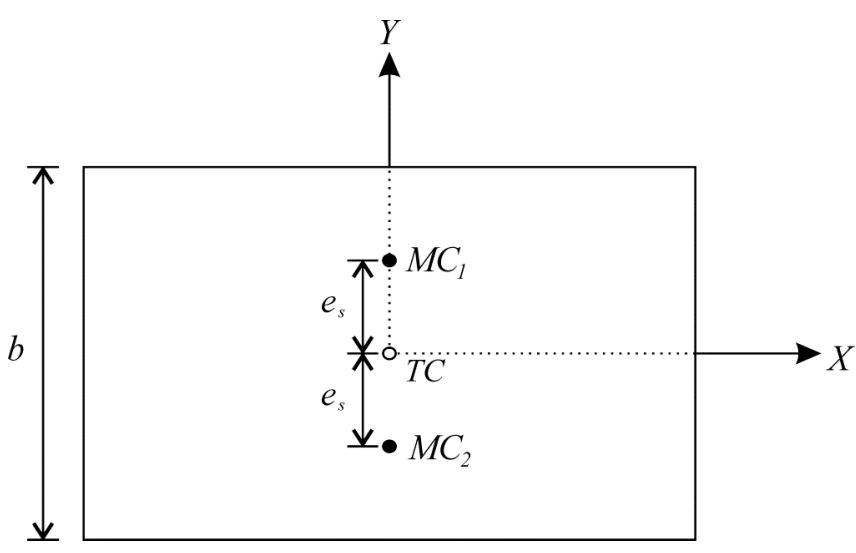

Fig. (8). Seismic eccentricity for analyses in $X$ direction.

Y

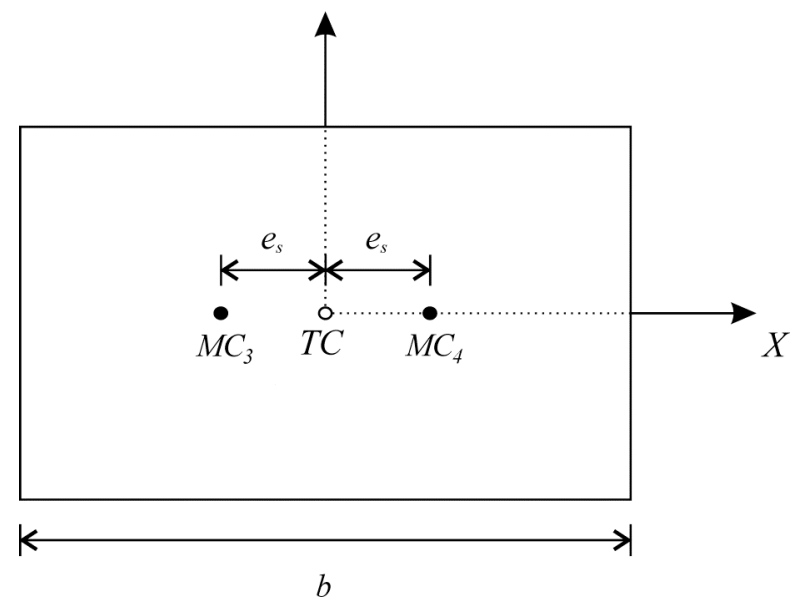

Fig. (9). Seismic eccentricity for analyses in $Y$ direction.

in the perpendicular direction is considered, as specified in [6] to take into account the bidirectional earthquake effects.

The analyses are performed using the modal spectral method, and considering the accidental eccentricity by moving the mass center $(M C)$ a distance $e_{s}= \pm 0.1 b$ transversal to the direction of the analysis. Fig. (8) shows two positions of the $M C$ for the analyses in $x$ direction, in relation to the position of torsional center (TC). Fig. (9) displays the additional positions for the $M C$ for the analyses in the $y$ direction.

All floor levels are considered rigid diaphragms. The translational properties are considered only for lateral loads ( $X$ and $Y$ directions); and the rotational properties perpendicular to the $X Y$ plane, are considered uniformly distributed when the $M C$ coincides with the $T C$ position. For the other four positions of the $M C$ the rotational properties are calculated according the mass distribution showed in Fig. (10). If it is not possible to locate the $M C$ at the desired position as shown in Fig. (10), then an alternate distribution is used as shown in Fig. (11). All mass centers are moved in the same directions in all floors at the same time.

In addition to checking the strength of structural elements, interstory drift for all floor levels must be assessed. Since this aspect of the design process is not directly related with stability and strength of the structure, and could be more related to functionality and comfort conditions, from 


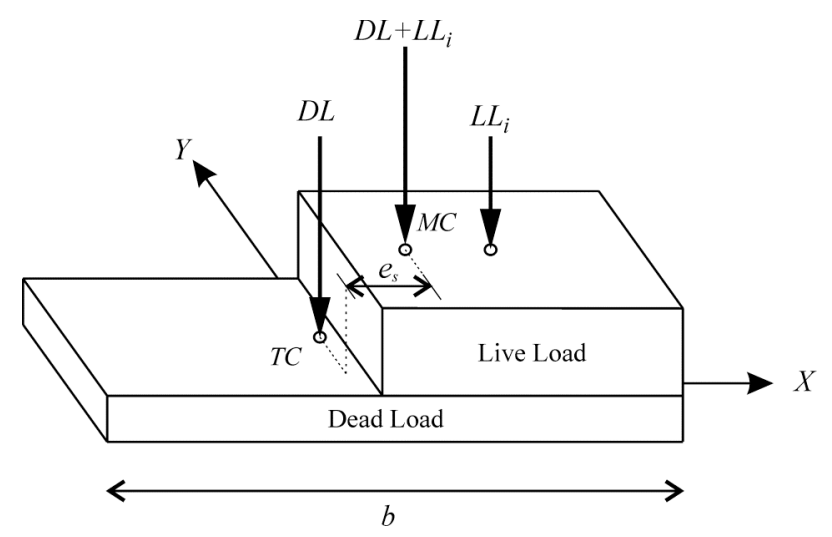

Fig. (10). Mass distribution to calculate torsional properties for each floor.

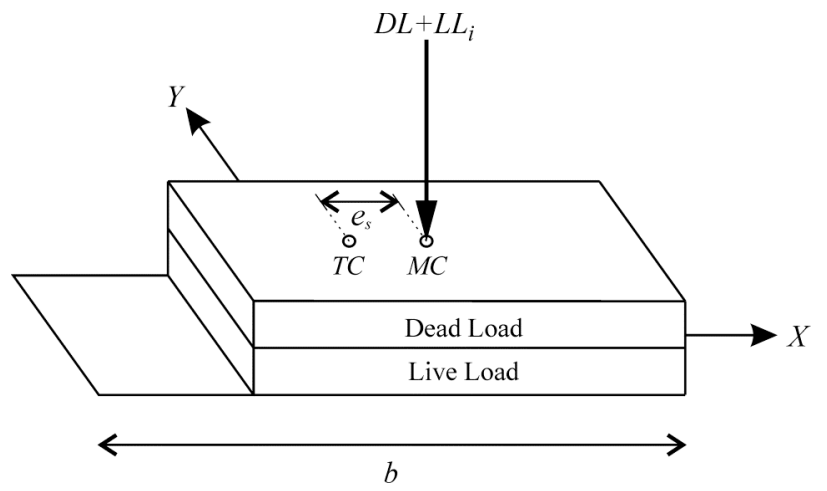

Fig. (11). Alternate mass distribution to calculate torsional properties.

now on, this part will be referred as service conditions. According to [6] the maximum interstory drift must be less than 0.006 times the story height, when structural and nonstructural elements are connected. If the structure has adequate gaps between structural and nonstructural elements, i.e., nonstructural elements are disconnected from the structure, interstory drift must be less than 0.012 times the story height. Lateral inelastic displacements are estimated multiplying by $\mu$ the displacements obtained from the linear-elastic analysis.

\section{RESULTS}

Fig. (12) shows the total amount of steel if only the strength requirements are considered in all the $\mathrm{W}$-shapes elements. As expected, as the seismic forces are reduced, the required strength of structural elements are reduced too, decreasing the required amount of material and therefore the initial cost of the structure.

Results shown in Fig. (12) would be good news for the owner of the structure, because it meant that the structure could be constructed with less money. However, sometimes the designer is not aware that this reduction in the initial cost could be not as good as expected, because if a strong earthquake occurs, the ductility demands, and therefore the level of damage in the structure, will be greater for the models designed with less lateral seismic force.

Fig. (13) shows the required amount of material when the strength and service conditions are considered, and the nonstructural elements are not connected to the structure, i.e., this is the final design used to build the structure. Note that for service conditions, Fig. (13) (and also Fig. 14) shows in red the additional required steel in relation to that required for strength conditions only (in blue). As can be noted, when $\mu=2$ is considered, there is only a reduction in the amount of material about $26 \%$ respect to linear elastic case $(\mu=1)$. Moreover for $\mu=3$ there is no reduction in the amount of material respect to the previous case $(\mu=2)$. It is important to note that the Mexican building code [6] permits reduction in the seismic forces up to 4 (i.e.: $\mu=4$ ); however, adequately detailed connections and construction requirements should be met to reduce the seismic forces by four times with respect to the linear-elastic case.

If nonstructural elements (walls, windows, doors, glasses, etc.) are connected to the structure, the required amount of material is shown in Fig. (14). It can be observed from the figure that the required material is incremented with respect to strength conditions even for the linear elastic case. The reduction of seismic forces for $\mu=2$ and $\mu=3$ has no effect in the final design. Details of the design of the structures as well the sections for all considered cases are available in [13].

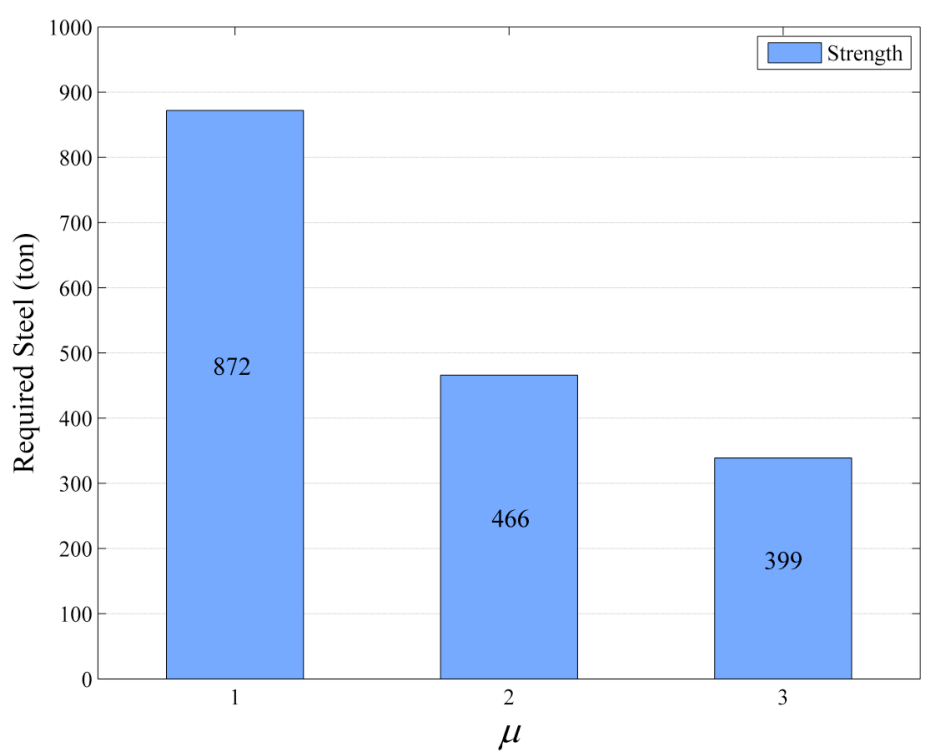

Fig. (12). Required steel for strength only. 


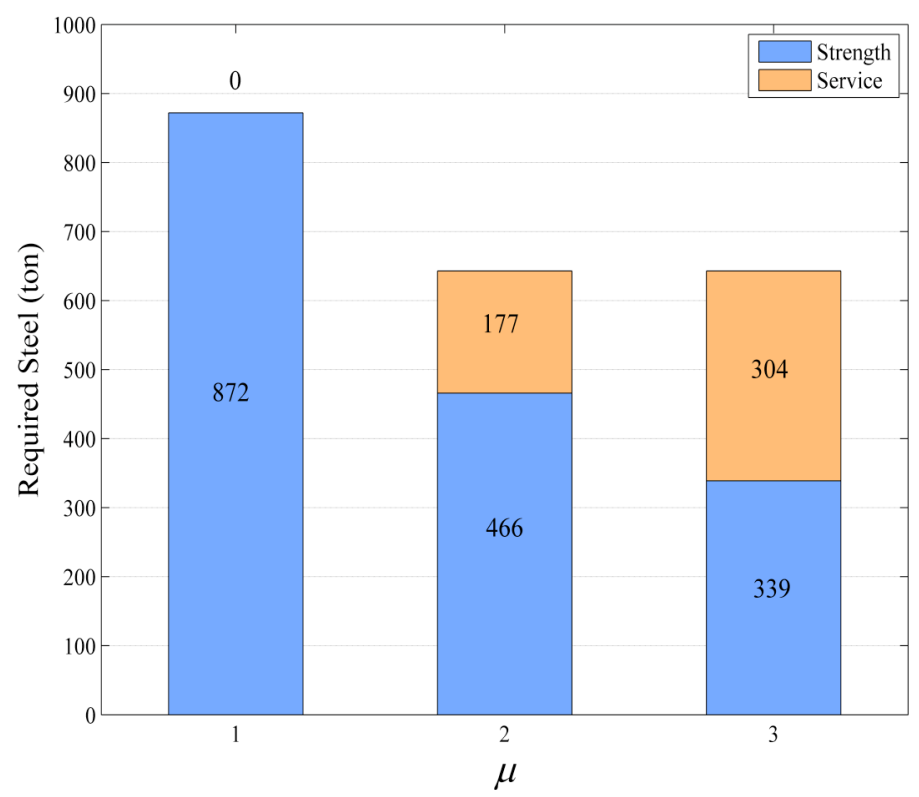

Fig. (13). Required steel for strength and service - Nonstructural elements disconnected.

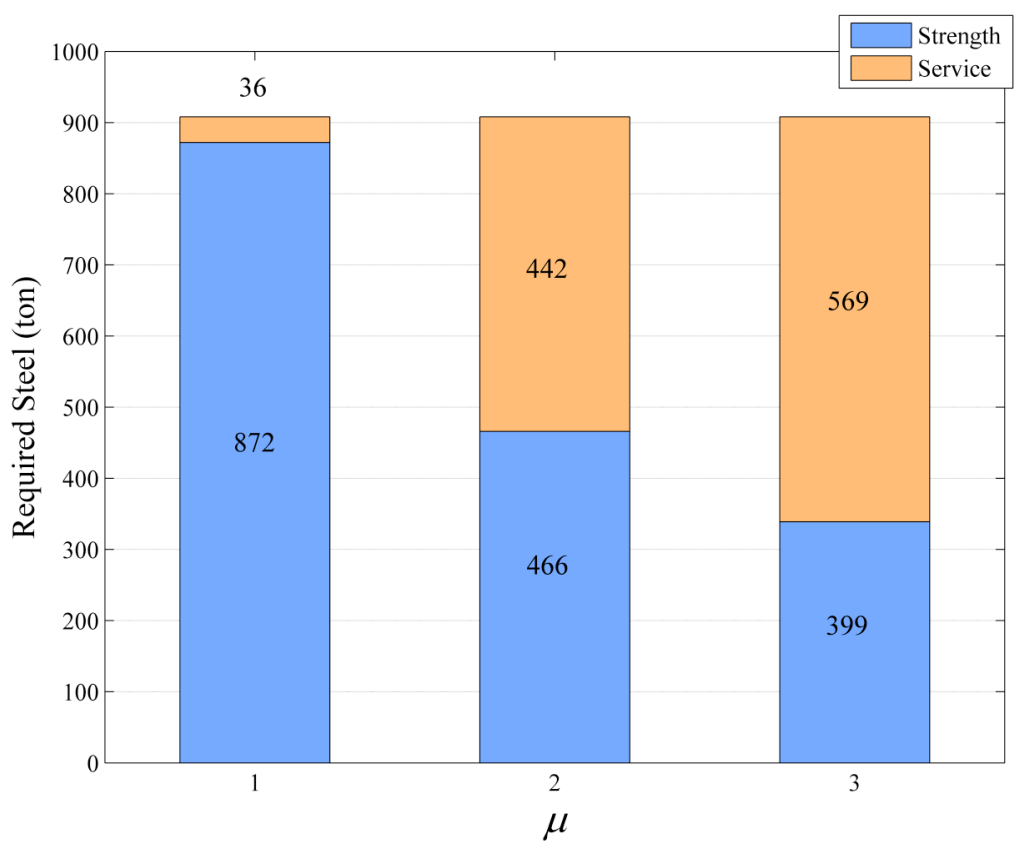

Fig. (14). Required steel for strength and service - Nonstructural elements connected.

\section{CONCLUSION}

Final designs according to Mexican regulations for building structures in low seismic demand regions are presented. The results show the amount of material required for the construction of the structures like an indirect but proportional measure of the cost of the structure since, at least in Mexico, the cost of steel construction is proportional to the weight of the structure.

The obtained results suggest that when a structure is designed with seismic force reduction in a low seismicity region, this procedure is only effective in decreasing the amount of needed material if the nonstructural elements are disconnected from the structure. For the study case a reduction of $26 \%$ for $\mu=2$ with respect to linear elastic case is reached. Further reduction of seismic forces has no effect on the final design, and can complicate the construction due to detailing and construction requirements as indicated in the current construction code. Considering that the cost of the structure may be about $30 \%$ of the total cost of the building, the above mentioned reduction in cost represents only about $8 \%$ saving in construction costs.

In areas with no history of strong earthquakes, it is common not to have appropriate detailing to decouple nonstructural components from the main structure. For this reason, the most representative results of realistic conditions are those shown in Fig. (14) in this study, where it is clear that no matter the level of seismic force reduction, it has no impact in the final design. Since the final design is the same no matter what value of seismic behavior factor is used, the 
seismic vulnerability of the structures are identical which is not consistent with the different seismic dissipation energy associated to a value of different seismic behavior factor.

It is noted that designs are carried out using building codes developed for regions with high seismic demands. Therefore, more extensive studies are needed to propose expression to take into account several parameters to design structures in different areas with different levels of seismic demand. For regions that are not seismic, the results suggest that reducing the seismic forces using the seismic behavior factor has no significant effect in the final design, at least in the current form of the Mexican regulations $[6,7]$.

\section{CONFLICT OF INTEREST}

The authors confirm that this article content has no conflict of interest.

\section{ACKNOWLEDGEMENTS}

The authors acknowledge the support of the Universidad de Guanajuato to develop the presented paper. Also, the authors thank the reviewers for their comments and suggestions which helped to improve this paper.

\section{REFERENCES}

[1] A. K. Chopra, Dynamics of Structures - Theory and Applications to Earthquake Engineering, $4^{\text {th }}$ Ed. Prentice Hall: New Jersey, USA, 2011.
[2] D. Arroyo-Espinoza, and A. Terán-Gilmore, "Factores de reducción de fuerzas sísmicas para el diseño de estructuras con sistemas pasivos de disipación de energía," Rev. Ing. Sísmica, vol. 66, pp. 73-93, 2002.

[3] R. Aguiar-Falconi, Diseño Sísmico de Edificios, Escuela Politécnica del Ejército, Ecuador, 2008.

[4] E. Bazán, and R. Meli, Diseño Sísmico de Edificios, LIMUSA, México, 2003.

[5] RCDF-04, Reglamento de Construcciones para el Distrito Federal. Gobierno del Distrito Federal, Gaceta Oficial del Distrito Federal, México, DF, 2004.

[6] NTC-04, Normas Técnicas Complementarias para Diseño por Sismo. Gaceta Oficial del Distrito Federal, México DF, 2004.

[7] MDOC-93, Manual de Diseño de Obras Civiles - Diseño por Sismo. Comisión Federal de Electricidad, México DF, 1993.

[8] NSR-98. Normas Colombianas de Diseño y Construcciones Sismorresistente. Asociación Colombiana de Ingeniería Sísmica, Tomo 1, Bogotá, 1998.

[9] CEC-2000. Código Ecuatoriano de Construcción. XIII Jornadas Nacionales de Ingeniería Estructural, Pontificia Universidad Católica de Ecuador, pp. 325-350, Quito, 2000.

[10] IBC-2012, International Building Code, International Code Council, Country Club Hills, Illinois USA, 2012.

[11] NTC-04, Normas Técnicas Complementarias para el Diseño y Construcción de Estructuras Metálicas, Gobierno del Distrito Federal, Gaceta Oficial del Distrito Federal, México DF, 2004.

[12] NTC-04, Normas Técnicas Complementarias Sobre Criterios y Acciones para el Diseño Estructural de las Edificaciones, Gobierno del Distrito Federal, Gaceta Oficial del Distrito Federal, México DF, 2004.

[13] A. E. Ortíz-Vargas, Influencia del factor de comportamiento sísmico en el diseño de un edificio de acero, Undergrade Dissertation, Civil Engineering Department, Guanajuato Campus, Universidad de Guanajuato, Mexico, 2011.

Received: October 07, 2014

(C) Hernández-Martínez et al.; Licensee Bentham Open.

This is an open access article licensed under the terms of the Creative Commons Attribution Non-Commercial License (http://creativecommons.org/licenses/ by-nc/3.0/) which permits unrestricted, non-commercial use, distribution and reproduction in any medium, provided the work is properly cited. 